\title{
EDITORIAL
}

\section{Social Psychology in Asia}

The Conference is jointly organized by the Asian Association of Social Psychology (AASP), the National Academy of Psychology, India and the Indian Institute of Technology, Delhi.Thethemeoftheconference,Identity,Multiculturalism and Changing Societies: Challenges for Social Psychology in and about Asia, has attracted not only psychologists but scholars from other disciplines such as sociology, literature, economics, philosophy and other branches of social sciences. This is not surprising as issues of identity and multiculturalism are important for policy-makers and planners, in fact the ever changing complexities of the modern world often compel us to confront anew those issues of identity and multiculturalism that have long been at the centre of public debates as well as academic discourses. Social scientists today are faced with a plethora of issues that demand re-analysis and comprehension at various levels - from the individuals to cultural groups to larger societies as a whole. Such a gamut of constant and instant transformations in the external world means that we all have to cope with multiple psychological demands that seem to strain the resources of 'childhood' and 'adulthood'. Consequently, fundamental redefinitions of the self appear inevitable in contemporary times. Celebration of difference, respect for pluralism, recognition of ethnic and minority status and the avowal and redefinition of identity are matters that every society is in its own way is grappling in recent times. The present conference provides a platform for professionals to share views and perspectives on dynamic new research that is, paradoxically, shaped by the very factors that they seek to investigate.

The present special issue of Psychological Studies comprises abstracts of addresses and presentations scheduled at the AASP Conference.

- Girishwar Misra, Purnima Singh (Editors) - Sanchita Srivastava, Saurabh Maheshwari and Tuheena Mukherjee (Assistant Editors) 